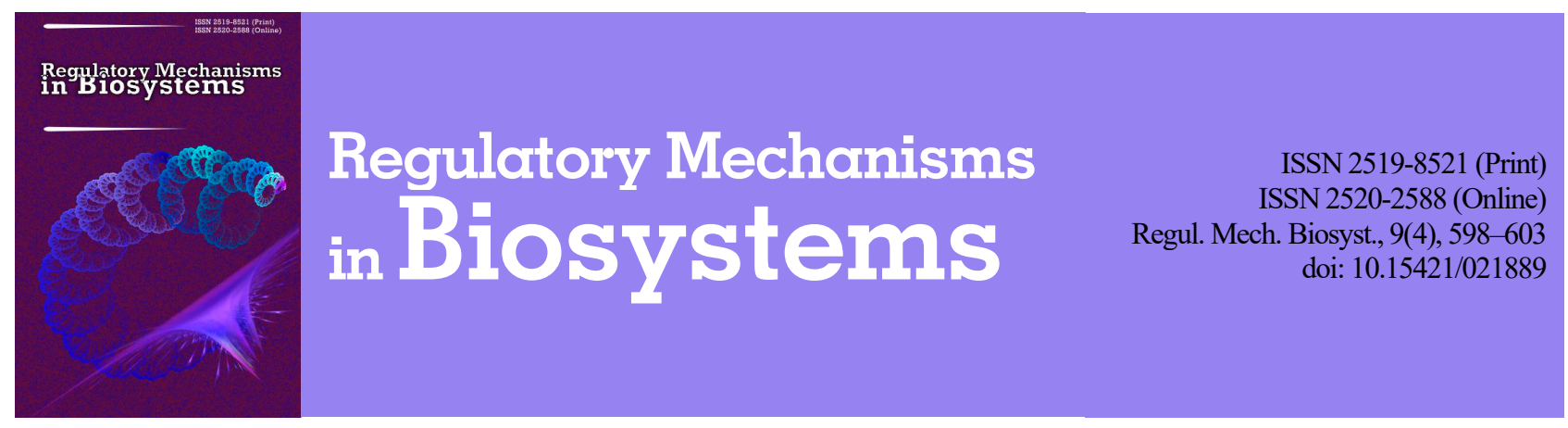

\title{
Age-related characteristics of spectral bioelectric activity of the trophotropic zone of the hypothalamus in female rats
}

\author{
V. V. Mukvych*, V. P. Lyashenko*, S. M. Lukashov** \\ *Oles Honchar Dnipro National University, Dnipro, Ukraine \\ **Medical-Diagnostic Scientific-Consulting Center "Headache”, Dnipro, Ukraine
}

\section{Article info \\ Received 10.10.2018 \\ Received in revised form 15.11.2018 \\ Accepted 18.11.2018}

Oles Honchar Dnipro National University,

Gagarin ave., 72,

Dnipro, 49010, Ukraine.

Tel.: +38-097-566-44-51.

E-mail:mukvichv@ukr.net

lyashenkovp@gmail.com

Medical-Diagnostic

Scientific-Consulting Center

"Headache",

Dnipro, 49010, Ukraine.

Tel.: +38-050-320-81-43

E-mail:

dr.lukashev@gmail.com

\author{
Mukvych, V. V., Lyashenko, V. P., \& Lukashov, S. M. (2018). Age-related characteristics of spectral bioelectric activity of the \\ trophotropic zone of the hypothalamus in female rats. Regulatory Mechanisms in Biosystems, 9(4), 598-603. doi:10.15421/021889
}

The purpose of the study was to determine the functional state of the trophotropic zone of the hypothalamus in female rats of different age groups according to bioelectric activity indices. Experiments were carried out on non-linear white outbred female rats. Animals were divided into IV groups: I group (2.5 months) - the juvenile puberty period, II group (eight months) - the young age of the reproductive period, III group (fourteen months) - the mature age of the reproductive period, IV group (21 months) - rats of presenile age of the pronounced senile changes period. Rats of the studied groups underwent Electric Hypothalamus Test (EGtG) of the trophotropic zone. The prevalence of low-frequency components of EGtG in female rats of the juvenile age and the domination of bioelectric activity in the delta range of the investigated hypothalamic region is determined. The young age in females was marked by an increase in all values of normalized spectral power, except the theta-like activity, which in turn was characterized by a possible decrease in the indices. In female rats, from young to presenile age, a gradual increase in the share of absolute power of high-frequency components of EGtG was observed, which was manifested in the functional activation of desynchronizing effect on bioelectric activity of the investigated hypothalamic region. There was an increase in theta-like and beta-like activity while there was a reduction in the percentage of alpha and especially delta wave power. In the female rats of the presenile age, the delta-like activity indices slightly recovered and exceeded those of mature female rats, theta and alpha-like activities underwent a significant decline in values and were represented by the lowest values, while beta-like activity was observed at the highest rates. However, it was precisely the mature female rats that showed a significant predominance of beta-like activity, which is evidence of the powerful desynchronizing mechanisms functioning. Electrophysiological indices indicate synaptic plasticity growth deficiency in female rats of the youngest age and factors of its degradation in those of presenile age, respectively. The power and the desynchronization rhythms representation increase is characteristic of the most productive age period with the most developed neurosynapticplasticity inherent to it.

Keywords: anterior hypothalamic area; EGtG; age; female rats

\section{Introduction}

The individual development of every living organism starting from the zygote formation to natural death is subject to age-related changes. In its turn, a certain age period in the ontogenesis of an organism is characterized by the corresponding features peculiar to it, which gradually develop in all physiological systems (respiratory, digestive, excretory, sensory, etc.), causing a decrease in functional activity of the organism (Lopez et al., 2017). The most sensitive and vulnerable are those systems that ensure the metabolism at the cellular level, namely transport (blood and lymphatic) and regulatory (endocrine, nervous, immune) systems (Chaudhary \& Rizvi, 2018). "The most advanced mechanism in the world" - the brain of a living organism, which also undergoes age-related changes, is not an exception. The laws of the brain development are a long-term process and are rather heterochronous according to its zones and levels at each age stage (Bischof \& Park, 2015). Instead, throughout life age-related changes, including the post-reproductive period of ontogenesis, which influence the brain, are also characterized by significant asynchrony. Thus, with age, certain uneven atrophic changes in the brain are observed, which are manifested in decrease in the number (by 10$20 \%$, in some zones - by 30-50\%) (Piechota \& Sunderland, 2014; Ray et al., 2018) and density (especially in the cerebellum, prefrontal and temporal lobe of cortex) (Hernandez et al., 2018) of neurons. Herewith the number of glial cells increases (Verkhratsky et al., 2014; Mecca et al.,
2018), the mass and volume of the brain decreases, while the size of its ventricles increases. Also, with age, the cerebral blood flow decreases (Zhou et al., 2018), as well as the ability of neurons to utilize glucose (Felsted et al., 2017). The levels of acetylcholine, noradrenaline, dopamine, serotonin, gamma-aminobutyric acid, homovanilinic acid and other neurotransmitters (Straathof et al., 2018; Jacob et al., 2018) decrease in different brain parts. This is due to the fact that with age, the activity of certain enzymes involved in the synthesis of neurotransmitters decreases (Vrankovic, 2016; Gomes de Andrade et al., 2018).

The hypothalamus is of considerable interest to scientists due to its involvement in ageing processes. It is known that one of the leading causes of aging of the body is the age-related changes in the hypothalamus (Satoh \& Imai, 2014). In this regard, the hypothalamus is considered to be a kind of "clock of aging" (Nakamura et al., 1984). According to V. M. Dilman - the hypothalamus - "conductor" of the endocrine system is the main link in the mechanisms of both the development and subsequent ageing of the body (Bezrukov, 1982). The age-related changes in the sensitivity of individual hypothalamic structures to nerve impulses, hormones and mediators, result in "mistakes" in information, both on the internal environment state and the homeostasis regulation. Thus, precisely because of inconsistencies in the "nervous" and "humoral" information flow, there is a violation of the relative stability of the composition and properties of the internal environment of the organism. The hypothalamus is a heterogeneous and structurally functional inhomogene- 
ous system, the corresponding characteristics of which are reflected in the uneven and different-directional development of age changes of its various nuclei. This is due to the fact that the hypothalamus has a division into zones that do not have clear boundaries but differ in their visceral effects during their activation (Kazakov \& Natrus, 2005). Hence, they distinguish the anterior region of the hypothalamus, the irritation of which results in predominantly parasympathetic (trophotropic) effects, whereas the activation of the posterior hypothalamus structures results in sympathetic (ergotropic) ones (Yoo \& Blackshaw, 2018). The trophotropic zone of the hypothalamus controls the regulation of homeokinesis, by activating anabolic processes. Its functional orientation is associated with a period of sleep and rest, increased activity of the digestive and excretory system. In this case, the activity of the trophotropic zone has a predominantly mobilizing effect on vago-insular apparatus (Musi \& Hornsby, 2015). The ergotropic zone contributes to the adaptation of the organism to conditions of a changing environment. It provides physical and mental activity, vegetative and motor activity, catabolic processes, using the apparatus of the segmental sympathetic vegetative nervous system (Zaec et al., 2014; Sharma et al., 2015).

Removal of bioelectric activity from the ergotropic zone of the hypothalamus is the main and in most cases the only indicator of determination of the course of central nervous processes, and allows study to be conducted of the functional state of this part of the brain. The method provides an opportunity to observe the dynamics of bioelectric activity of the trophotropic and ergotropic zones of the hypothalamus (Won et al., 2012; Falconi-Sobrinho et al., 2017). Most modern studies are based either on coverage of the anatomical and morphological features, or on the functioning of the hypothalamus and some of its nuclei under the influence of various kinds of medical preparations and chemicals, vortex pulsed magnetic field and electrical stimulation, stress, certain diseases, administration of hormones, mediators, etc. (Zadorozhna \& Ljashenko, 2008; Vetrile et al., 2013; Chaus et al., 2015; Bischof \& Park, 2015; Nabbi-Schroeter et al., 2018). Research on characteristic features of agerelated changes in the hypothalamus has produced some quite opposite hypotheses. Some researchers believe that with age, the hypothalamus functions weaken, which leads to numerous metabolic and functional changes in the body. Others argue that, on the contrary, ageing activates genetically programmed increase in the activity of the hypothalamus (Amenta et al., 1991; Sebastião \& Ribeiro, 2009; Aveleira et al., 2015).

In this context, the laboratory animals used in relevant studies in most cases belong to two age groups, namely: juvenile age of puberty and young age of reproductive period (Yadegari et al., 2016; Maslukov et al., 2016; Raghunathan et al., 2018). This is due to the fact that from a physiological point of view, these age groups of animals represent the most productive activity of the organism. Mature and presenile rats considerably complicate the experimental part of the study since they require a sufficient amount of time to reach the appropriate age for entering a given age group. No studies were found that are based on the age-related dynamics of spectral bioelectric activity of the trophotropic zone of the hypothalamus of females in the age groups of our rats. Given the above, our experiments were conducted on four age groups of rats the juvenile, young, mature, and presenile age of the period of pronounced age-related changes. Analyzing the literature on relevant topics, we also noticed that most studies used only males (Zadorozhna \& Ljashenko, 2008; Brockhaus et al., 2018), which makes it impossible to carry out an objective sex comparison of certain indicators of the control groups within an experiment. For the experimental part of the study, males are most often used, rather than females since one needs to take into account the frequent effects of cyclic changes in the hormonal regulation of females. Instead, in our study, for the purpose of analyzing and comparing not only the peculiarities of age-related changes in the bioelectric activity of the trophotropic zone of the hypothalamus, we used rat females, taking into account the important aspect of cyclic changes in hormonal regulation. This gives us the opportunity to talk about the age-related dynamics of sex characteristics of the bioelectric activity of the anterior hypothalamic region of rats. The purpose of research was to determine the functional state of the trophotropic zone of the hypothalamus in female rats of different age groups according to bioelectric activity indices.

\section{Materials and methods}

The animal care and experiments met the requirements of "European Convention for the Protection of Vertebrate Animals Used for Experiments and Other Scientific Purposes" (Strasbourg, 2005), "General Ethical Principles of Animal Experiments", adopted by the Fifth National Congress on Bioethics (Kyiv, 2013).

The experiments were carried out on non-linear, white outbred female rats. The animals were divided into studied groups using the age classification of laboratory animals by Zapadniuk et al. (1983). According to the classification, the rats were divided into IV groups: I group (2.5 months) - the juvenile puberty period ( $\mathrm{n}=24)$, II group ( 8 months) - the young age of the reproductive period $(n=24)$, III group (14 months) - the mature age of the reproductive period $(n=21)$, IV group ( 21 months $)$ - rats of presenile age of the pronounced senile changes period $(n=18)$.

Before the experimental part of our work, the rats which were part of the study group were quarantined under the rules of zoohygiene. Female rats of the age categories were kept under standard conditions for laboratory animals, namely in well lit premises with a constant temperature of $20-25^{\circ} \mathrm{C}$ and humidity $40-45 \%$. The animals lived under standard conditions, with four rats in a cage with an area of $0.15 \mathrm{~m}^{2}$ $(0.3 \times 0.5 \mathrm{~m})$. Based on this, the area per animal was $375 \mathrm{~cm}^{2}$. The cages were cleaned regularly. Every week, disinfection was carried out with scalding boiled water and 5-10\% solution of caustic alkali. The diet of animals was based on the calculation of daily needs. On average, it is $30-32 \mathrm{~g}$ for rats, of which $25 \mathrm{~g}$ is mixed cereal feed, 5-7 $\mathrm{g}-$ vegetables. Rats had free access to drinking water. Thus, the animals of the respective study groups lived under standard conditions, i.e. sufficient temperature level, illumination and humidity in the vivarium, as well as normal diet and unlimited drinking water.

For the formation of homogeneous groups of female rats with more or less similar individual-typological peculiarities, the "open field" technique was used. In order to avoid data unreliability, two hours before testing the animals using the "open field" method, they were neither regrouped, fed, nor did they undergo any other manipulations. Moving from one cage to another, labeling and other similar procedures were carried out with animals at least 24 hours prior to testing.

Rats of the studied groups underwent Electric Hypothalamus Test (EGtG) of the trophotropic zone. The corresponding hypothalamic zone bioelectric activity registration was carried out under the conditions of an acute experiment on a polygraph $\mathrm{P} 6 \mathrm{CH}-1$ using standard electrophysiological equipment with a 16-bit analog-to-digital converter with a quantization frequency of $512 \mathrm{~Hz}$ (O. O. Bogomolets Institute of Physiology, Kyiv). Surgical preparation for performing EGtG removal was performed after intraperitoneal administration of thiopental sodium $(50 \mathrm{mg} / \mathrm{kg})$ and ketamine $(20 \mathrm{mg} / \mathrm{kg})$. The animal was fixed in a stereotactic device and underwent trepanation of the skull, the fixation site was infiltrated with a local anesthetic. When the first motor activity appeared, a needle unipolar electrode (Nihrom, diameter $100 \mu \mathrm{m}$ ) with varnish insulation except for the tip was injected in the neocortex. The electrode was immersed into the investigated hypothalamus zone using a manipulator. The removal of biopotentials of the structures was carried out under the atlas's coordinates (Paxinos \& Watson, 2005). Coordinates of the trophotropic zone of the hypothalamus (anterior hypothalamic area - AHA): bregma $(\mathrm{B})=-1.4$; lateral axis $(\mathrm{L})=0.08$; interaural axis $(\mathrm{I})=0.9$. The indifferent electrode was fixed on the animal's external ear. In all recordings of bioelectric activity, the duration of the analysis period was $60 \mathrm{~s}$ with sampling frequency of df equal to $0.1 \mathrm{~Hz}$.

To remove boundary effects, a Hamming window was used. We evaluated the spectral power of bioelectric activity of the trophotropic zone of the hypothalamus in the frequency range from 0.5 to $30 \mathrm{~Hz}$. The EGtG spectral composition was determined, namely, the percentage of waves power of a certain range relative to the total power of all oscillations was registered. Under the recommendations of the International Federation of Societies for Electroencephalography and Clinical Neurophysiology, we applied the classification of EGtG oscillations by frequency ranges: delta waves $-0.5-3.5 \mathrm{~Hz}$, theta waves $-4-7 \mathrm{~Hz}$, alpha waves -8 $13 \mathrm{~Hz}$, beta waves $-14-30 \mathrm{~Hz}$ (obviously, in the analysis of EGtG oscillations, it is more correct to refer to alpha and beta ranges as alpha- 
and beta-like activity). At the end of each experiment, the animals were decapitated.

Further processing of registered Electric Hypothalamus Test was carried out using the program "Exsperiment" (O. O. Bogomolets Institute of Physiology, Kyiv) and a package of applications in the MathCAD 15.0. The statistical processing of the results obtained during the experimental part of the research on female rats of different age categories was conducted using Origin 6.0 Professional by pair comparison method. We calculated the average value and the average value error. Reliability was determined using the ANOVA $(\mathrm{P}<0.05)$.

\section{Results}

The power of the absolute waves within the frequency range of $0.5-3.5 \mathrm{~Hz}$ in female rats of the juvenile age of the puberty period was $18.5 \pm 1.6$. With the age the corresponding indicator did not change, so in young female rats, we observed quite similar power values of deltalike activity compared with the results of female rats of the previous age period (Fig. 1). Instead, in the future, a somewhat stable situation, which was fixed in the age-related dynamics of the power of delta-oscillations in the trophotropic zone of the hypothalamus, was characterized by gradual changes. At the same time, there was a tendency to increase, which influenced the indicators of absolute power of delta-like activity in female rats of the mature age of the reproductive period. It should be noted that the power of the delta-like rhythm in female rats of the presenile age with respect to the manifestation of this EGtG frequency component in rats of other represented age groups was the highest and was $39.3 \pm 1.3$. To that end, female rats of presenile age were characterrized by a probable increase in the values of the power of the waves of the delta-range by 2.1 times compared with the females of the juvenile and younger ages. It is worth paying attention to the fact that in the agerelated dynamics of the absolute power of delta-like activity, the indices of this EGtG frequency component underwent a sharp increase just after the mature age in female rats. Thus, we can say that the modulation of the absolute power of waves of the delta-range of the corresponding zone of the rat hypothalamus is marked by changes in each stage of ontogenesis presented to us, except for the females of the juvenile and young age, of the puberty period and the reproductive period, respectively. According to the results of our study, both of them differed by practically the same values of the power of the lowest EGtG frequency component. In the females of the next age group, namely, the mature age of the reproductive period, there was a gradual increase in the absolute power of the delta-like rhythm, which with age changed to a sharp increase of the corresponding indicator, which was registered in presenile female rats.

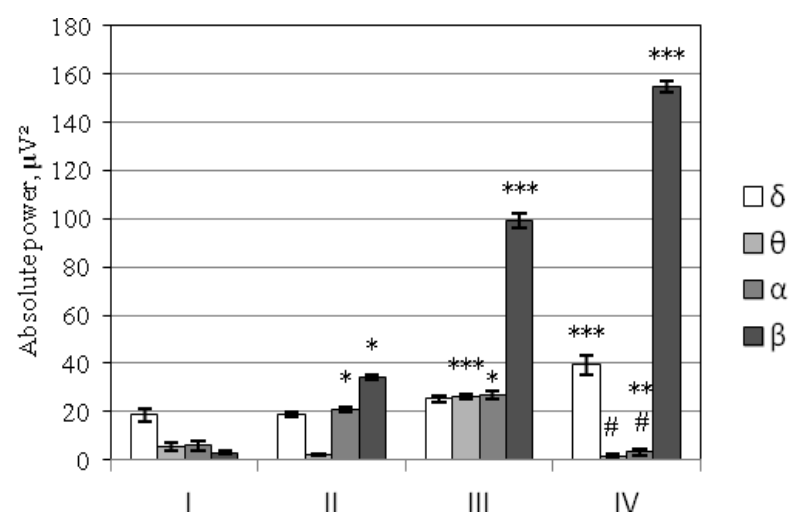

Fig. 1. Dynamics of absolute power of oscillations of Electric Hypothalamus Test (EGtG), removed from the trophotropic zone of the hypothalamus of female rats of juvenile age of puberty period (I), young age of the reproductive period (II), mature age of the reproductive period (III), presenile age of the pronounced senile changes period (IV): * - the probability of differences between the rats of juvenile age and the represented age groups of animals $(\mathrm{P}<0.05)$;** the probability of differences between the rats of young age and the represented age groups of animals ( $P<0.05)$; $\#-$ the probability of differences between the rats of presenile age and the represented age groups of animals $(\mathrm{P}<0.05)$
Analyzing the absolute power of the theta-like activity in the trophotropic zone of the hypothalamus in female rats, it should be understood that the corresponding indicator is a reflection of the signs of stress and the effect of stress load (Vorobeva \& Koljadko, 2007). This indicator in female rats of juvenile age was $5.3 \pm 0.8$. With age there was a tendency to decrease in the power in the range from 4 to $7 \mathrm{~Hz}$ in the investtigated area of the hypothalamus, which affected the indicators of young female rats. Female rats of the mature age of the reproductive period had the highest values of the manifestation of this EGtG frequency component, removed from the trophotropic zone of the hypothalamus. It is worth paying attention to the fact that the indices of absolute power of oscillations of the theta range of the studied area of the hypothalamus in female rats of the mature age are probably higher by 4.9 and by 13.0 times compared with female rats of the juvenile and younger age, respectively. Instead, quite high indices of the power of the theta-like activity were characterized by a sharp decrease with age. It was in the rats of the presenile age that the minimum power of this range was registered, which is by 15.7 times lower compared to the corresponding indices of mature female rats. Consequently, the dynamics of the absolute power of the thetalike activity in the EGtG spectral composition of female rats with age undergoes significant probable changes. From this perspective, Figure 1 shows how the gradual decrease in the theta-range oscillations power of female rats of the juvenile and younger age is changed by a significant probable increase (to $26.3 \pm 1.6$ ) in the next age group of rats. After that, in female rats of the pre-senile age group, there was a sharp decrease of the index to its lowest value, which was quite close to the results of the theta-like power in female rats of the young age.

Dynamics of indices of alpha-like activity in the trophotropic zone of the hypothalamus in female rats with age differed significantly from the presented age-related changes of the remaining EGtG components. The alpha-range oscillations power indices in female rats of the juvenile age are believed to be by 3.6 times lower than those of the young rats of the reproductive period. Thus, given the above, we observed a rather rapid increase in the values of alpha-like activity in the corresponding area of the hypothalamus of female rats already in their second age period under study. With age, alpha-range oscillations power indices tended to increase and reached their maximum values in the trophotropic zone of the hypothalamus of female rats of mature age. The corresponding indicator was probably higher by 4.7 times compared with female rats of juvenile age. Instead, the next age period in the development of female rats was characterized by radical changes in the dynamics of this high-frequency EGtG component. We observed a sharp decrease in the absolute power of alpha-like activity (up to $3.1 \pm 0.6$ ) in presenile female rats, which were probably lower by 6.6 and 8.6 times compared with the corresponding indices of young and mature female rats. Also, the power of the oscillations in the range under consideration in female rats of the presenile age was reflected in the form of the smallest values among the rest of the analyzed results in female rats of different age groups. Summarizing the above, it should be noted that the age dynamics of the power of alphalike activity in the studied area of the hypothalamus in female rats with age is not marked by the stability of indices in the corresponding range, but is rather characterized by significant probable changes.

Having made a general analysis of the results of the absolute power of beta-like activity in the trophotropic zone of female rats of different age groups, it should be noted that their indices increased to some extent during our study. Thus, females of the juvenile age of the puberty period were characterized by minimum values of power within the beta-range. Instead, the power indices of the EGtG component in young female rats were by 11.8 times higher than that of females of the youngest age group. The presented data indicate the rapid increase in the beta-like activity power in the trophotropic zone of the hypothalamus of young female rats. The next age period of female rats was also not an exception to the general tendency of a sharp increase in the power indices of the betarange oscillations. In mature female rats the probable increase of this index was by 33.9 and 2.9 times in comparison with female rats of juvenile and young age, respectively. The maximum power, which was recorded in the range from 14 to $30 \mathrm{~Hz}$ in the trophotropic zone of the hypothalamus, was observed in female rats of presenile age. On this basis, this index by 53.1 and 4.5 times was significantly higher than the corresponding values of the beta- 
like activity power in female rats of the juvenile and younger age. Thus, as the observations show, a rapid increase in the corresponding indices at each of their age-stages is a characteristic feature in the dynamics of the beta-range oscillations power in the female rat hypothalamus area.

According to the results of the study, it can be stated that with the age the spectral power dynamics of the lowest EGtG frequency component, i.e. the activity of the delta-range in the trophotropic zone of the hypothalamus in female rats undergoes significant changes at each age stage (Fig. 2). The highest percentage of delta-like activity in comparison with indices of female rats of other age groups belongs to female rats of juvenile age $(58.2 \pm 3.7 \%)$. Thus, the values of the spectral power of the delta range waves of the corresponding area of the hypothalamus in the female rats of the youngest age are believed to be higher by 4 and 3 times compared with the mature and presenile female rats, respectively. The young age of female rats is characterized by a tendency to a sharp decline (by $42 \%$ ) of delta-like activity compared with female rats of the previous age group. Instead, the tendency to the spectral power decrease in the frequency range of $0.5-3.5 \mathrm{~Hz}$, was observed later with age, and female rats of the mature age of the reproductive period were not an exception. Female rats of this age were characterized by the minimum percentage of delta-like activity indices $(14.6 \pm 1.1 \%)$ compared with females of other age categories. Female rats of the presenile age are marked by an increase in the spectral power of the delta-range oscillations in the trophotropic zone of the hypothalamus and are by 1.3 times higher than indices of female rats of the mature age. Thus, among the entire EGtG spectral composition of the corresponding area of the hypothalamus in female rats of the juvenile age, the quantity of waves in the delta-range exceeded the rest of their frequency components. In view of the above, we can say that with age, the values of normalized spectral power of delta-like activity in trophotropic area of the hypothalamus in female rats are significantly decreased to those of presenile age. Instead, in the last age group of female rats the vector of the process, which we observed during the three

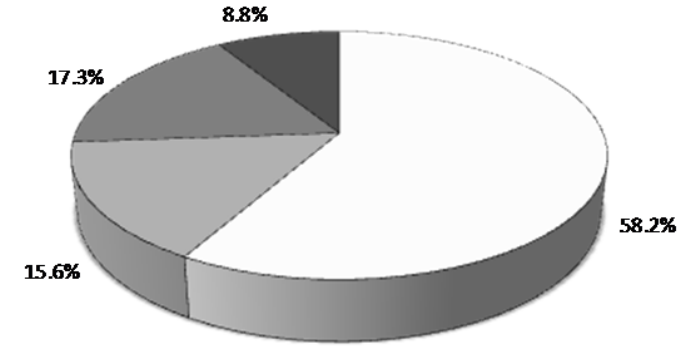

$\square \boldsymbol{\delta} \square \boldsymbol{\theta} \square \boldsymbol{\alpha} \square \beta$

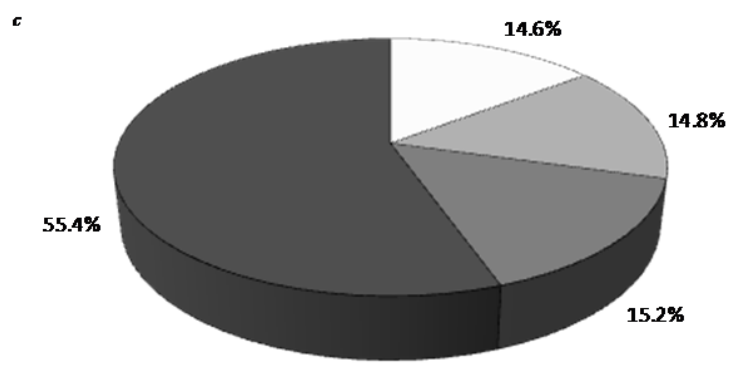

$\square \boldsymbol{\delta} \square \boldsymbol{\theta} \square \boldsymbol{\alpha} \square$ age periods, changed in the opposite direction. In this regard, in female rats of the presenile age, a significant increase in the spectral power of the delta-range oscillations is observed, which exceeds the same indices in female rats of the mature age and is by 1.3 times lower compared to the corresponding values in young female rats.

The age dynamics of the percentage values of the theta-like activity of the trophotropic zone of the hypothalamus in female rats of different age groups showed no stability or certain regularity in changes of bioelectric activity indices in the corresponding range. It is appropriate to note that changes in the normalized spectral power of the theta-like activity with age are practically opposite to the delta-like activity in the hypothalamus area under study. Theta-like activity indices among other EGtG frequency components in female rats of juvenile age were $15.6 \pm$ $0.6 \%$, which in its turn is likely to be almost 6 times higher compared with female rats of the young age. Thus, we observed a probable rapid decrease in spectral power in the frequency range of $4-7 \mathrm{~Hz}$ in 8 month old female rats. Instead, the female rats of the next age group experienced a significant increase in the percentage values of the theta-range oscillations power in the trophotropic zone of the hypothalamus. The obtained indices of theta-like activity in female rats of the mature age were practically close to the mentioned values of female rats of juvenile age, although they were somewhat lower. In female rats of the presenile age, this index has sharply decreased to values noticeably lower than those recorded in female rats of young age and amounted to $1.4 \pm 0.6 \%$, which is believed to be lower by almost 11 times compared with female rats of juvenile age. The corresponding percentage of bioelectric activity within the thetarange of the trophotropic zone is a reflection of the minimum index of the studied activity among female rats of all age groups. The above results of the bioelectric activity of one of the low-frequency EGtG components of the hypothalamus area indicate significant sharp variations, which are manifested in an increase and a sudden decrease in the values, or vice versa, which are observed with age in the studied female rats.

$\boldsymbol{b}$

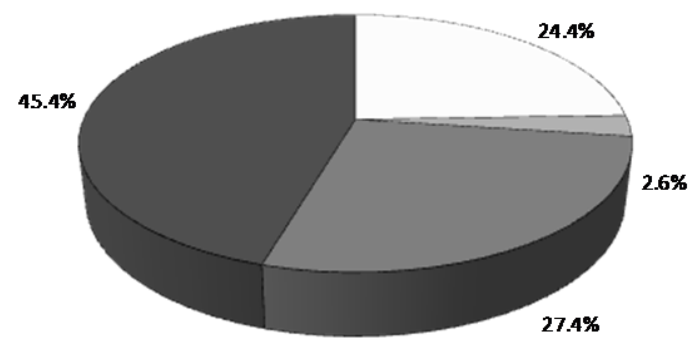

$\square \boldsymbol{\delta} \square \boldsymbol{\theta} \square \boldsymbol{\alpha} \square$

$\boldsymbol{d}$

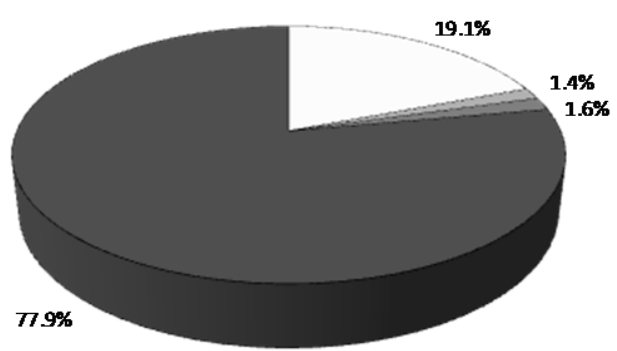

$\square \boldsymbol{\delta} \square \boldsymbol{\theta} \square \boldsymbol{\alpha} \square$

Fig. 2. Dynamics of the normalized spectral capacities (\%) of the EGtG frequency components, removed from the trophotropic zone of the hypothalamus of female rats of juvenile age of puberty period $(a)$, young age of the reproductive period $(b)$, mature age of the reproductive period $(c)$, presenile age of the pronounced senile changes period $(d)$

The dynamics of the EGtG frequency components power, removed from the trophotropic zone of the hypothalamus, namely the alpha-like activity, was characterized by the absence of probable age-related changes in the indices of female rats of the first three age groups. Instead, we observed a tendency to increased values of normalized spectral power of the alpha-range oscillations in the corresponding area of the hypotha- lamus of female rats of young age (up to $27.4 \pm 1.2 \%$ ) compared to female rats of the juvenile age group. Subsequently, the opposite tendency was observed with age and a significant decrease in alpha-like activity in female rats was registered in comparison with female rats of young age and a rather moderate decrease in the corresponding index compared with female rats of the youngest age group. It is worth paying attention 
to the lowest values of the alpha-like activity power, which were noted in female rats of the presenile age of the period of pronounced age-related changes and amounted to $1.6 \pm 0.2 \%$. Thus, female rats of the last studied age group were characterized by a probable decrease in the normalized spectral waves power of the given range in the trophotropic zone of the hypothalamus by 10.9 and 17.2 times compared with the female rats of the juvenile and young age, respectively. Summarizing the above, a noteworthy detail is that with age, female rats experienced oscillations in the alpha-like activity values in two opposite directions (they both increased and decreased), while there was no probability evidence. Instead, after completion of mature age, a significant sharp decrease in the power percentage indices of the frequency range from 8 to $13 \mathrm{~Hz}$ of the trophotropic zone of the hypothalamus was observed, which was evidenced in female rats of presenile age.

It should be noted that the age-related dynamics of percentage values of the beta-like activity of the trophotropic zone of the hypothalamus of female rats in comparison with the alpha-like activity of the investigated area and the corresponding sex of animals was completely the opposite. Thus, in female rats of the juvenile age, the normalized spectral power of the beta-range waves was normalized to $8.8 \pm 1.2 \%$. This index was the lowest beta-like activity value among female rats of other age groups. The next age period of female rats was accompanied by a rapid increase of the corresponding indices to $45.3 \pm 1.3 \%$, which stated a probable increase in the beta-range oscillations power in the trophotropic zone of the hypothalamus by 5 times compared with the female rats of the youngest age. In female rats of mature age, a rather moderate tendency towards the growth of these indices was observed, although we noted their probable increase compared to female rats of juvenile age. Subsequently, with age, we again observed a repeated significant increase in bioelectric activity within the beta-range in the trophotropic zone of the hypothalamus that influenced the female rats of the presenile age. By comparing all the values of the corresponding component of the EGtG spectral composition of the investigated area in the female rats of different ages, we can say that the maximum index, namely $77.9 \pm 1.4 \%$ belongs to the female rats of the last presented age group. Thus, we can note that the age-related dynamics of beta-like activity within the EGtG, removed from the trophotropic zone of the hypothalamus in the female rats of the considered age categories, was characterized by interweaving both sharp and gradual increases in their values, the peak of which fell on female rats of the presenile age.

Summing up the study results of the spectral bioelectric activity dynamics of the trophotropic zone of the hypothalamus of female rats of different age groups, we can outline some characteristic age-related features. Female rats of the juvenile age were characterized by the predominance of low-frequency EGtG components and domination of the delta-range bioelectric activity of the investigated hypothalamic area. The young age of female rats was marked by an increase in all values of normalized spectral power, except for the theta-like activity, which in its turn was characterized by a possible decrease of indices. At this age period, we observed the predominance of high-frequency components of the EGtG spectral composition of the corresponding area of the hypothalamus, which was also evidenced in the next age group of female rats, although there were little significant differences in the showing of tendency. There was an increase in theta-like and beta-like activities against the background of decrease of percentage values of power in alpha- and delta-range waves in particular. The aforementioned tendency regarding the predominance of high-frequency EGtG components, removed from the trophotropic zone of the hypothalamus was reflected in the female rats of the presenile age. Thus, the delta-like activity indices slightly recovered and exceeded those of mature female rats, theta- and alpha-like activities underwent a significant decrease in the indices and were presented with the lowest values, while the beta-like activity was marked by the highest values.

\section{Discussion}

Based on the data obtained, we can conclude that the delta-like activity of female rats of the juvenile age was the dominant power among other EGtG components. So the predominance of slow-wave synchronization processes in the form of low-frequency high-amplitude bioelectric activity predominance in the trophotropic zone of the hypothalamus was traced back in the female rats of the youngest age group. Change in the frequency of the dominant rhythm of electric activity of the brain is regarded as an index of the change in the functional mobility of the neurons: its slowing down causes the decrease in the lability of the neurons, frequency increase - their functional mobility increase. Simultaneous functional mobility changes of large groups of neurons are the focal point of stationary excitation, which determines the rhythmic activity synchronization process. Some authors (Kinawy et al., 2014; Finnema et al., 2015) believe that the existence of humoral mechanisms of electric activity synchronization related to active substances of endogenous nature affecting synapses is possible. Meanwhile, with change in the age periods in female rats, significant changes were observed in the dynamics of absolute power of all EGtG components, removed from the investigated area of the hypothalamus. In female rats, starting from the young to presenile age, we observed a gradual increase in the high-frequency EGtG components absolute power share, which was manifested in the functional activation of desynchronizing effect on bioelectric activity of the corresponding area of the hypothalamus. However, it was precisely the female rats of the presenile age that characterized a significant predominance of beta-like activity, which is evidence of the powerful functioning of desynchronizing mechanisms.

The study results give an opportunity to formulate ideas on mechanisms of occurrence of the Electric Hypothalamus Test dynamics of female rats in different age groups. Probably the changes in neurophysiological characteristics in this part of the brain are due to the corresponding dynamics of synaptic plasticity (Nakamura et al., 1984; Patterson, 2015; Dulcis, 2016; Cole et al., 2017). From our point of view, the low level of differrentiation of mediator absorption postsynaptic receptors promotes a synchronized response to postsynaptic neurons. Thus, the smaller the number of postsynaptic receptors, the lower the frequency of the Hypothalamus Test (Piechota \& Sunderland, 2014). The lowest level of this index corresponds to the delta-like rhythm frequency. With age, the synthetic activity of the presynaptic neurons gradually increases, which leads to a relevant increase in the absolute rhythm power in animals from the first to the fourth groups (Straathof et al., 2018). The spectral power of this rhythm reduces with age, which is due to the gradual increase in the desynchronized rhythmic vibrational activity. Thus, there is a gradual dominance of the theta-like rhythm that is typical for mature rats. This phenomenon, in our opinion, is due to an increase in the number of postsynaptic receptors that are actively differentiated with age (Raghunathan et al., 2018). Concurrently, the mature age shows the power increase of the alpha- and beta-like rhythms characterizing the degree of growth of desynchronous postsynaptic response to mediator neurotransmission (Masliukov et al., 2016). In the fourth group of animals, spectral power of the theta-like rhythm was the highest, and absolute power was minimal, which can result from a significant reduction in the neurosynthetic activity of presynaptic neurons in the background of initial degradation of the number of differentiated postsynaptic receptors (Arivazhagan \& Panneerselvam, 2002; Li \& Rieckmann, 2014). The latter fact is confirmed by the adequate increase in the absolute power of the delta rhythm in this group of rats. Particular attention is attracted by the dynamic reduction in spectral power against a sharp increase in the absolute power of the most desynchronous high-frequency beta-like rhythm in this group of animals. This phenomenon is a logical confirmation of the glutamate modeling effect on synaptic neurotransmission (Vranković, 2016; Zhang et al., 2018) in the context of relative reduction of neurotransmitter quanta as a result of age-related inhibition of the synthetic activity of presynaptic neurons (Tan et al., 2014). It is likely that this permanent excitotoxic effect of glutamate is the beginning of a stage of apoptotic neurodegenerative changes in the central nervous system of rats of the senile age (Brockhaus et al., 2018).

\section{Conclusions}

In female rats of juvenile age, the prevalence of slow-wave synchronization processes was recorded in the form of the predominance of low-frequency high-amplitude of the bioelectric activity in the trophotropic zone of the hypothalamus. 
The prevalence of high-frequency oscillations among the entire EGtG spectral composition was observed in female rats of young and mature age, as reflected in the functional activation of the desynchronizing influence on bioelectrical activity of the respective hypothalamus area.

According to the study results, the female rats of the presenile age had the highest indices of the amplitude and frequency of beta-range waves compared to the female rats of the other represented age groups, which is also an evidence of the powerful functioning of desynchronizing mechanisms.

\section{References}

Amenta, F., Zaccheo, D., \& Collier, W. L. (1991). Neurotransmitters, neuroreceptors and aging. Mechanisms of Ageing and Development, 61(3), 249-273.

Arivazhagan, P., \& Panneerselvam, C. (2002). Neurochemical changes related to ageing in the rat brain and the effect of DL-alpha-lipoic acid. Experimental Gerontology, 37(12), 1489-1494.

Aveleira, C. A., Botelho, M., \& Cavadas, C. (2015). NPY/neuropeptide Y enhances autophagy in the hypothalamus: A mechanism to delay aging? Autophagy, 11(8), 1431-1433.

Bischof, G. N., \& Park, D. C.(2015). Obesity and aging: Consequences for cognition, brain structure, and brain function. Psychosomatic Medicine, 77(6), 697-709.

Brockhaus, K., Böhm, R. R., Melkonyan, H., \& Thanos, S. (2018). Age-related beta-synuclein alters the p53/Mdm2 pathway and induces the apoptosis of brain microvascular endothelial cells in vitro. Cell Transplantation, 27(5), 796-813.

Chaudhary, M. K., \& Rizvi, S. I. (2018). Erythrocyte senescence in a model of rat displaying Hutchinson-Gilford progeria syndrome. Analytical Cellular Pathology, 2018, 5028925.

Chaus, T. G., Ljashenko, V. P., \& Tkachenko, J. O. (2015). Zagal'na kharakterystyka elektrychnoji aktyvnosti gipotalamusu shhuriv za umov stresu ta prygnichennja kateholergichnoji nejroperedachi rezerpinom [General characteristic of electric activity of hypothalamus of rats in the conditions of stress and inhibition of neurotransmission using reserpine]. Prirodnichij Almanah, 41, 167-181 (in Ukrainian)

Cole, D. C., Chung, Y., Gagnidze, K., Hajdarovic, K. H., Rayon-Estrada, V., Harjanto, D., Bigio, B., Gal-Toth, J., Milner, T. A., McEwen, B. S., Papavasiliou, F. N., \& Bulloch, K. (2017). Loss of apobeC1 RNA-editing function in microglia exacerbates age-related CNS pathophysiology. Proceedings of the National Academy of Sciences, 114(50), 13272-13277.

Dulcis, D. (2016). The ever-changing brain: Clinical implications. Journal of Chemical Neuroanatomy, 73, 1-2.

Falconi-Sobrinho, L. L., Anjos-Garcia, T. D., de Oliveira, R., \& Coimbra, N. C. (2017) Decrease in NMDA receptor-signalling activity in the anterior cingulate cortex diminishes defensive behaviour and unconditioned fear-induced antinociception elicited by GABAergic tonic inhibition impairment in the posterior hypothalamus. European Neuropsychopharmacology, 27(11), 1120-1131.

Felsted, J. A., Chien, C. H., Wang, D., Panessiti, M., Ameroso, D., Greenberg, A., Feng, G., Kong, D., \& Rios, M. (2017). Alpha2delta-1 in SF1+ neurons of the ventromedial hypothalamus is an essential regulator of glucose and lipid homeostasis. Cell Reports, 21(10), 2737-2747.

Gomes de Andrade, G., Reck Cechinel, L., Bertoldi, K., Galvão, F., Valdeci Worm, P., \& Rodrigues Siqueira, I. (2018). The aging process alters IL-1 $\beta$ and CD63 levels differently in extracellular vesicles obtained from the plasma and cerebrospinal fluid. Neuroimmunomodulation, 25(1), 18-22.

Hernandez, A. R., Reasor, J. E., Truckenbrod, L. M., Campos, K. T., Federico, Q. P., Fertal, K. E., Lubke, K. N., Johnson, S. A., Clark, B. J., Maurer, A. P., \& Burke, S. N. (2018). Dissociable effects of advanced age on prefrontal cortical and medial temporal lobe ensemble activity. Neurobiology of Aging, 30(70), 217-232.

Kazakov, V. N., \& Natrus, L. V. (2005). Modulation of neuronal impulse activity of the anterior hypothalamus as a functional basis of the mechanisms underlying hypothalamic control. Neurophysiology, 37, 463-474.

Kinawy, A. A., Ezzat, A. R., \& Al-Suwaigh, B. R. (2014). Inhalation of air polluted with gasoline vapours alters the levels of amino acid neurotransmitters in the cerebral cortex, hippocampus, and hypothalamus of the rat. Experimental and Toxicologic Pathology, 66(5-6), 219-224.

Li, S. C., \& Rieckmann, A. (2014). Neuromodulation and aging: Implications of aging neuronal gain control on cognition. Current Opinion Neurobiology, 29, 148-158.

Lopez, T. P., Giles, K., Dugger, B. N., Oehler, A., Condello, C., Krejciova, Z., Castaneda, J. A., Carlson, G. A., \& Prusiner, S. B. (2017). A novel vector for transgenesis in the rat CNS. Acta Neuropathologica Communications, 5(1), 84.

Masliukov, P. M., Emanuilov, A. I., \& Nozdrachev, A. D. (2016). Developmental changes of neurotransmitter properties in sympathetic neurons. Advances in Gerontology, 29(3), 442-453.
Mecca, C., Giambanco, I., Donato, R., \& Arcuri, C. (2018). Microglia and aging: The role of the TREM2-DAP12 and CX3CL1-CX3CR1 axes. International Journal of Molecular Sciences, 22, 19(1), e19010318.

Musi, N., \& Hornsby, P. (2015). Handbook of the biology of aging. 8th edition. Academic Press, New York

Nabbi-Schroeter, D., Elmenhorst, D., Oskamp, A., Laskowski, S., Bauer, A., \& Kroll, T. (2018). Effects of long-term caffeine consumption on the adenosine a1 receptor in the rat brain: An in vivo PET study with $\left[{ }^{18} \mathrm{~F}\right] \mathrm{CPFPX}$. Molecular Imaging and Biology, 20(2), 284-291.

Nakamura, S., Yamao, S., Iijima, S., Kaji, R., Kameyama, M., Miyata, S., Itoh, J., \& Mimori, Y. (1984). Age-related changes in nervous system. Nihon Ronen Igakkai Zasshi, 21(3), 209-213.

Patterson, S. L. (2015). Immune dysregulation and cognitive vulnerability in the aging brain: Interactions of microglia, IL-1 $\beta, \mathrm{BDNF}$ and synaptic plasticity. Neuropharmacology, 96(A), 11-18

Paxinos, G., \& Watson, C. (2005). The rat brain in stereotaxic coordinates. 5-th edition. Academic Press, New York

Piechota, M., \& Sunderland, P. (2014). Neuronal aging. Postepy Biochemii, $60(2), 177-186$.

Ray, S., Corenblum, M. J., Anandhan, A., Reed, A., Ortiz, F. O., Zhang, D. D., Barnes, C. A., \& Madhavan, L. (2018). A role for Nrf2 expression in defining the aging of hippocampal neural stem cells. Cell Transplantation, 27(4), 589-606.

Satoh, A., \& Imai, S. (2014). Systemic regulation of mammalian ageing and longevity by brain sirtuins. Nature Communication, 26(5), 4211.

Sebastião, A. M., \& Ribeiro, J. A. (2009). Adenosine receptors and the central nervous system. Handbook of Experimental Pharmacology, 193, 471-534

Sharma, R. K., Choudhary, R. C., Reddy, M. K., Ray, A., \& Ravi, K. (2015). Role of posterior hypothalamus in hypobaric hypoxia induced pulmonary edema. Respiratory Physiology Neurobiology, 205, 66-76.

Straathof, M., Sinke, M. R., van der Toorn, A., Weerheim, P. L., Otte, W. M., \& Dijkhuizen, R. M. (2018). Differences in structural and functional networks between young adult and aged rat brains before and after stroke lesion simulations. Neurobiology of Disease, 18, 30393.

Tan, F. C., Hutchison, E. R., Eitan, E., \& Mattson, M. P. (2014). Are there roles for brain cell senescence in aging and neurodegenerative disorders? Biogerontology, 15(6), 643-660.

Verkhratsky, A., Rodríguez, J. J., \& Parpura, V. (2014). Neuroglia in ageing and disease. Cell and Tissue Research, 357(2), 493-503.

Vorobeva, T. M., \& Koljadko, S. P. (2007). Jelektricheskaja aktivnost' mozga (priroda, mehanizmy, funkcionalnoe znachenie) [The electrical activity of the brain (the nature, mechanisms, functional significance)]. Jeksperimentalnaja i Klinicheskaja Medicina, 2, 4-11.

Vranković, J. (2016). Age-related changes in antioxidant and glutathione Stransferase enzyme activities in the asian clam. Biochemistry, 81(3), 224-232.

Won, S. H., Jang, H. S., Lee, H. W., Jang, I. S., \& Lee, M. G. (2012). Evaluation of brain functional states based on projections of electroencephalographic spectral parameters on 2-dimensional canonical space. Neuroscience Methods 211(1), 40-48

Yadegari, M., Khazaei, M., Anvari, M., \& Eskandari, M. (2016). Prenatal caffeine exposure impairs pregnancy in rats. International Journal of Fertility Sterility, 9(4), 558-562.

Yoo, S., \& Blackshaw, S. (2018). Regulation and function of neurogenesis in the adult mammalian hypothalamus. Progress in Neurobiology, 54(2), 71-88.

Zapadnjuk, I. P., Zapadnjuk, E. A., \& Zaharija, E. A. (1983). Laboratornye zhivotnye: Razvedenie, soderzhanie, ispolzovanie $\mathrm{v}$ eksperimente [Laboratory animals: Breeding, maintenance, and use in experiments]. Vishha Shkola, Kyiv (in Ukrainian)

Zaec, N. S., Ljashenko, V. P., Burceva, D. O., Lukashov, S. M., \& Melnikova, O. Z (2014). Adaptacijni reakciji nejrosinaptichnoji aktyvnosti ergotropnoji zony gipotalamusa shhuriv za umov luzhnogo racionu [Adaptational reactions of neurosynaptic activity of ergotropic zone of hypothalamus of rats in the conditions of alkaline ration]. Vcheni Zapiski Tavrijskogo Nacionalnogo Universitetu im. V. I. Vernadskogo, Biologija, Himija, 27, 46-55 (in Ukrainian).

Zhang, B., Gong, J., Zhang, W., Xiao, R., Liu, J., \& Xu, X. Z. S. (2018). Brain-gut communications via distinct neuroendocrine signals bidirectionally regulate longevity in C. elegans. Genes Development, 32(3-4), 258-270.

Zhou, Y. F., Li, P. C., Wu, J. H., Haslam, J. A., Mao, L., Xia, Y. P., He, Q. W. Wang, X. X., Lei, H., Lan, X. L., Miao, Q. R., Yue, Z. Y., Li, Y. N., \& Hu, B. (2018). Sema3E/PlexinD1 inhibition is a therapeutic strategy for improving cerebral perfusion and restoring functional loss after stroke in aged rats. Neurobiology Aging, 70, 102-116. 